\title{
Hur inverkar \\ organisationsstrukturen på socialtjänstens klientarbete? - en sammanfattning av kunskapsläget
}

\section{PÄR GRELL, NADER AHMADI \& BJÖRN BLOM}

Organisatorisk specialisering präglar dagens sociala arbete. Konsekvenserna av denna specialisering har dock inte studerats vetenskapligt i någon större utsträckning. Spänningsfältet mellan organisatorisk specialisering och dess motpol integrering är utgångspunkten för denna artikel, som sammanfattar och diskuterar kunskapsläget när det gäller hur olika organisationslösningar inverkar på socialtjänstens klientarbete.

\section{Inledning}

Socialt arbete är mångfacetterat och inbegriper ett flertal strategier och arbetssätt för att lösa ett stort antal sociala problem

Pär Grell, doktorand i socialt arbete, Akademin för hälsa och arbetsliv, Högskolan i Gävle.

Nader Ahmadi, docent i sociologi, Akademin för hälsa och arbetsliv, Högskolan i Gävle.

Björn Blom, professor i socialt arbete, Institutionen för socialt arbete, Umeå universitetet. av skilda slag. Därmed spänner även forskningen om socialt arbete över ett stort område, där mängder av studieobjekt, teoretiska utgångspunkter och forskningsdesigner är möjliga. I detta brokiga forskningsfält är forskningen om särskilda sociala fenomen, klientgrupper, eller kategorier av sociala problem samt specifika behandlingsmetoder, mest framträdande (Dellgran \& Höjer 2011). En forskningsöversikt av Johansson (2005) visar att forskningen om de organisationer där det sociala arbetet 
bedrivs, däremot är mindre utbredd. Organisationsdimensionen har dock stor spännvidd och återfinns bland annat i studier av organisationsförändringar (Martin \& Hazlett-Knudsen 2012), ledarskap (Boehm \& Yoels 2009), organisationskultur (Shim, 2009), samt organisationens betydelse för de anställdas hälsa och välmående (Shier \& Graham 2011).

Andra aspekter av det sociala arbetets organisering är emellertid delvis förbisedda av forskningen. Ett sådant område är de formella organisatoriska ramarnas - organisationsstrukturens - betydelse för hur socialtjänstens klientarbete gestaltar sig och vad det åstadkommer (Martin \& HazlettKnudsen 2012). Svensk forskning har i detta avseende uppmärksammat en kunskapslucka när det gäller konsekvenserna av den utbredda och tilltagande organisatorska specialisering som präglar socialtjänsten. Det vill säga, vilka blir följderna då åtskilda delar eller specifika funktioner inom en och samma organisation ansvarar för avgränsade arbetsuppgifter riktade mot olika problemområden eller målgrupper? I synnerhet anses specialiseringens konsekvenser ur ett klientperspektiv vara dåligt belysta (Andersson \& Sallnäs 2007, Bergmark \& Lundström 2005, Blom et al. 2009, Lundgren et al. 2009, Meeuwisse et al. 2011).

Organisatorisk specialisering är dock inte något unikt för svensk socialtjänst. Det rör sig snarast om ett globalt fenomen som präglar de flesta samhällssektorer, varav socialtjänstområdet är ett av dem (Fisher \& Elnitsky 2012, Healy \& Meagher 2007, Parton 2009, Sousa \& Rodrigues 2009). Specialisering inom socialtjänsten och dess internationella motsvarigheter har däremot inte alltid varit norm. I USA och Storbritannien, liksom i de nordiska länderna, har integrerade organisationer där arbetet riktas mot ett bredare fält av sociala problem - haft större anseende och utbredning under 1970- talet och 1980talets första hälft (Bergmark \& Lundström 2007, Bømler 2012, Dickens 2011, Hassett \& Austin 1997, Parton, 2009).

Även om renodlad integrering är en sällsynt organisationsstruktur i dagens sociala arbete, så kan den ur organisationsteoretisk synvinkel betraktas som en ytterlighet $i$ ena änden av ett kontinuum, där den höggradigt specialiserade organisationen befinner sig i motsatt ände. På en glidande skala mellan dessa poler kan ett antal organisatoriska mellanformer lokaliseras, bland annat beroende på arten och graden av samverkan mellan berörda parter. I detta avseende kan koordination respektive kollaboration sägas representera två steg utefter kontinuumet (Boklund 1995).

Inom socialtjänstområdet har spänningsfältet mellan integrering och specialisering, liksom frågan om hur olika organisationsstrukturer inverkar på klientarbetet, varit föremål för återkommande diskussioner i den vetenskapliga litteraturen. (Bergmark \& Lundström 2005, Blom et al. 2009, Buck et al. 2011, Cambridge \& Parkes 2006, Dickens, 2011, Green et al.2005, Healy \& Meagher 2007, Johansson 2005, Lundgren et al. 2009, Martin \& Hazlett-Knudsen, 2012, Meeuwisse et al. 2011, Parton 2009, Perlinski 2010, Stevenson 2005, Villadsen 2008). Medan åsikterna delvis skiljer sig åt i detta ämne, finns en samsyn angående behovet av mer forskning inom området. På ett generellt plan kan sådan forskning

Grell, Ahmadi \& Blom: Hur inverkar organisationsstrukturen på.. 
motiveras av att socialtjänstorganisationen utgör en avgörande länk mellan stat och medborgare när välfärdspolitikens intentioner ska förverkligas (Hasenfeld 2010a). Vidare har socialtjänstens utrednings- och behandlingsmetoder hamnat allt mer i fokus, då idén om evidensbaserad praktik (EBP) fått spridning. Dessa metoder torde vara svåra att studera och värdera om de separeras från de strukturella arrangemang som de ingår i (Johansson 2005).

Sammantaget kan alltså socialtjänstorganisationens struktur och strukturens konskevenser för klientarbetet, betraktas som ett relevant forskningsområde där det tillika finns ett behov av mer forskning men vad vet vi egentligen idag? Syftet med denna artikel är att, utifrån spänningsfältet mellan organisatorisk specialisering och integrering, sammanfatta och diskutera kunskapsläget när det gäller hur olika organisationsstrukturer inverkar på det klientarbete som utförs inom svensk socialtjänst och dess internationella motsvarigheter.

Artikeln disponeras på följande sätt: Efter beskrivningen av metod och material definieras ett antal centrala organisationsteoretiska begrepp. Därefter redovisas i tur och ordning det som i litteraturen talar för respektive emot organisatorisk specialisering och integrering inom socialtjänstområdet. Detta följs av en redogörelse för styrkor och svagheter med kollaboration respektive koordination - två organisatoriska "medelvägar" i förhållande till ytterligheterna specialisering och integrering. Avslutningsvis diskuteras resultatet $\mathrm{i}$ relation till frågan om hur socialtjänstens arbete bör organiseras, samt vilka frågor som kan vara relevanta för framtida forskning.

\section{Metod och material}

Denna artikel har den narrativa kunskapsöversiktens prägel och skiljer sig därmed från den utpräglat systematiska översikten. Intentionen är att åstadkomma en övergripande förståelse av kunskapsläget inom ett relativt komplext och delvis outforskat område, snarare än att finna forskningsevidens i en avgränsad fråga (Collins \& Fauser 2005). Det innebär i sin tur en mer förutsättningslös och förhållandevis bred litteratursökning, liksom att studiens resultat växer fram i en process som präglas av viss subjektivitet (Bryman 2011). Den metod som använts i denna studie är därigenom svårare att beskriva, i synnerhet i korta ordalag. Därför finns det skäl att beskriva tillvägagångssättet något mer utförligt.

De sökmotorer som använts för litteratursökning är Academic Search Elite (EBSCO), Discovery, Google Scholar, PsykINFO, Scopus, Social Services Abstracts, Sociological Abstracts, samt Web of Science (SCI-EXPANDED, SSCI). Inledningsvis användes olika kombinationer av sökord som specialization, differentiation, integration, generic, holistic, social work, social agencies, organizations och human service organisations, samt dessa begrepps nordiska motsvarigheter. Flest träffar gav kombinationerna av de för studien centrala termerna "social work" och "specialization"(närmare 60 träffar), respektive "integration" (uppemot 350 träffar). Vid en läsning av abstracts visade sig det stora flertalet av artiklarna sakna relevans för denna studie, då de till exempel behandlade specialisering och integrering 
kopplat till frågor som organisationsförändring, ledarskap, arbetsklimat eller organiserandet av socialarbetarutbildningar. Endast ett fåtal artiklar visade sig beröra kopplingen mellan organisationens utformning och klientarbete explicit. Mycket få behandlade empiriska studier i ämnet, och bland dessa hittades endast 10 studier där specialiserade och integrerade organisationsformer jämfördes i något avseende.

En bredare sökstrategi befanns nödvändig för att uppnå studiens syfte och den fortsatta litteratursökningen inspirerades bland annat av nyckelord och referenser i materialet från den initiala sökningen. Litteratursökning och urval, samt analys av materialet kom att bli en närmast sammanflätad process där en kvalitativ och riktad innehållsanalys (Hsieh \& Shannon 2005) tillämpades. De ursprungliga sök- och analyskategorierna specialisering och integrering kompletterades i detta skede med koordinering respektive kollaboration för att införliva den relativt omfattande forskningen om organisatorisk samverkan i översikten, och för att därmed nyansera bilden av potentiella organisatoriska arrangemang inom socialtjänstområdet. Inkluderingskriteriet för den litteratur som söktes fram i denna process blev huruvida respektive text kopplade samman organisatorisk specialisering, koordinering, kollaboration eller integrering med konsekvenser för klientarbete $\mathrm{i}$ något avseende. Därutöver ägnades särskild möda åt att medvetet söka efter litteratur där respektive organisationsstrukturs styrkor och svagheter belystes.

Detta urvals- och analysförfarande utmynnade i de 81 texter som bildar under- lag till artikelns resultatavsnitt. Majoriteten utgörs av vetenskapliga artiklar som genomgått peer-review (51 stycken). Men även böcker (12), doktorsavhandlingar (9), rapporter från universitet, myndigheter och organisationer (7), samt konferenspaper (2) ingår i materialet.

I detta sammanhang bör det nämnas att svensk socialtjänst saknar exakta motsvarigheter vid en internationell jämförelse. Även gränsdragningarna mellan olika välfärdaktörer och deras målgrupper varierar länder emellan. Internationella artiklar har inkluderats om de berör de områden som normalt sorterar under svensk socialtjänst, det vill säga ekonomiskt bistånd, missbruks- och barnavård, äldre- och handikappomsorg, samt i viss mån socialpsykiatri. På grund av de variationer som finns angående hur välfärdssektorn är indelad, tangerar vissa artiklar även andra välfärdsområden som exempelvis hälso- och sjukvård. Med detta sagt är ändå utgångspunkten för översikten att likheterna är betydligt större än skillnaderna mellan olika länders socialtjänster. I synnerhet gör sig spänningsfältet mellan organisatorisk specialisering och integrering påmint oavsett nationell kontext.

\section{Spänningsfältet mellan specialisering och integrering ur ett organisationsteoretiskt perspektiv}

Inom organisationsteori avser specialisering och integrering två av de element som konstituerar en organisations struktur, det vill säga två av de formella faktorer som påverkar hur arbetet utförs, samt vem som utför

Grell, Ahmadi \& Blom: Hur inverkar organisationsstrukturen på.. 
arbetet (Scott 2003). Specialisering och integrering har även en vertikal dimension som avser hierarkiska nivåer i en organisation, liksom en horisontell dimension där professioner, arbetsuppgifter och eventuella specialiteter är i fokus (Axelsson \& Bihari Axelsson 2006). Det är i huvudsak den horisontella dimensionen som denna artikel berör. Specialisering handlar enkelt uttryckt om varierande grad av arbetsdelning och fokusering på avgränsade arbetsuppgifter (Scott 2003). Den vanligaste formen av specialisering inom socialtjänstområdet är att arbetet med olika typer av sociala problem - som ekonomiskt bistånd, missbruksfrågor eller barnavård - försiggår i separata enheter. Detta brukar benämnas problemspecialisering, medan så kallad funktionsspecialisering innebär att utredande och beslutsfattande i en organisation skiljs från stödjande och behandlande aktiviter (Bergmark \& Lundström 2005, Blom et al. 2009).

Begreppet integrering används på varierande sätt i den organisationsteoretiska litteraturen. Engelskans integration kan till exempel syfta på olika former av samarbete eller samverkan. Både mellan separata välfärdsorganisationer, eller mellan enheter i en och samma organisation (Hassett \& Austin 1997, Horwath \& Morrison 2005). Men begreppet kan även användas för att karaktärisera en "integrerad" organisation, med ett brett spektra av funktioner och arbetsmetoder, och som vänder sig till flera olika målgrupper (Fisher \& Elnitsky 2012).

Här används emellertid begreppen specialisering och integrering för att beskriva ett motsattsförhållande när det gäller organisationsstruktur (Se även Bergmark \& Lundström 2005, Cambridge \& Parkes 2006, Stevenson 2005). Utpräglat specialiserade eller integrerade organisationer kan betraktas som två polära idealtyper (Eriksson 1989) som är svåra att finna i renodlad form. I realiteten kan olika mellanformer när det gäller organisationslösningar snarare urskiljas utefter en glidande skala mellan de två motpolerna. I denna studie används begreppet samverkan som en överordnad och allmän term för olika typer av interaktion som försiggår mellan organisationer, eller mellan enheter i en och samma organisation. För att åskådliggöra hur kontinuumet mellan specialisering och integrering innehåller olika grader av sådan samverkan tillämpas här den terminologi för olika samverkansformer som bland annat använts av Boklund (1995).

Med utgångspunkt i den ena av ytterligheterna kan självständiga och specialiserade enheter existera sida vid sida och vända sig till skilda eller gemensamma målgrupper, utan att någon faktisk interaktion sker mellan enheterna. Detta kan betecknas

\section{Fig. I.}

Specialisering, koordination, kollaboration och integrering som ett kontinuum.

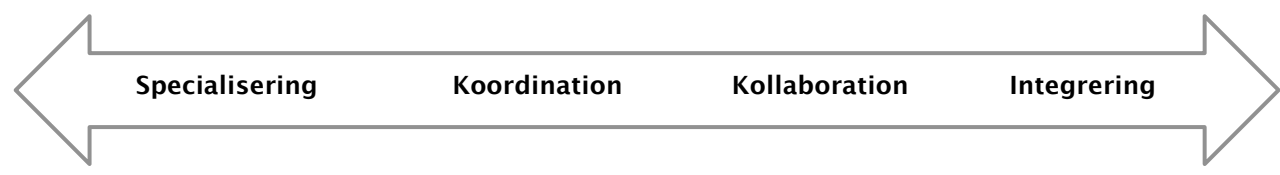


som separation eller icke-samarbete. Ett första steg utefter kontinuumet, i riktning mot integrering, kan fångas i termen koordination, där insatser från organisatoriskt åtskilda aktörer samordnas på olika sätt. Från att insatser genomförs i en viss ordning, till att inblandande aktörer håller varandra informerade vad som äger rum i respektive verksamhet. Aktörerna har dock kvar sina egna ansvarsområden och sina specifika arbetsuppgifter. Däremot innebär nästa steg, kollaboration, att gränserna mellan olika aktörer luckras upp något, samt att de inblandade bidrar med sina speciella kompetenser för att lösa uppgifter som i högre grad är gemensamma. I kontinuumets andra ände återfinns slutligen organisatorisk integrering, eller sammansmältning, där ett bredare spektrum av målgrupper och arbetsuppgifter införlivats i en och samma organisation.

Den resultatredovisning som följer härpå har tematiserats med ovanstående kontinuum som utgångspunkt. För att tydliggöra skillnaderna mellan motpolerna specialisering och integrering inleds emellertid framställningen med dessa två strukturers för- och nackdelar. En redogörelse för styrkor och svagheter som är förbundna med koordination respektive kollaboration avslutar därefter resultatavsnittet.

\section{Resultat}

\section{Rationalitet och expertis- specialiseringens fördelar}

Inledningsvis kan det vara motiverat att uppehålla sig vid några av de mer teore- tiskt grundade motiven för organisatorisk specialisering. Bevekelsegrunderna kan spåras ända tillbaka till de tidigaste organisationsteoretiska verken, som med tillverkningsindustri som utgångspunkt, argumenterade för specialisering. Principer som har fortsatt att prägla tänkandet om varuproducerande organisationer fram till idag (Eriksson-Zetterquist et al. 2006). Även författare som tidigt behandlade administrativa processer och byråkrati, associerade specialisering med effektivitet och produktivitet. Tydligt avgränsade enheter eller ämbeten, där ansvar och kompetens kunde renodlas, betraktades som avgörande för en rationellt fungerande administration (Fayol 1916/2007, Weber 1926/2007). Medan den första organisationsteoretiska vågen främst betraktade organisationer som slutna system och hade organisationers inre liv i fokus, kom senare strömningar att intressera sig mer för hur organisationer samspelar med sin omgivning (Scott 2003). Utifrån ett sådant perspektiv är en organisations framgång och livslängd, bland annat beroende av hur väl graden av specialisering motsvarar och matchar de krav och förväntningar som finns i det omgivande samhället (Lawrence \& Lorsch 1967). I linje med detta ligger ett av de mest framträdande incitamenten för specialisering inom socialtjänstområdet. Argumentationen bygger på att vare sig enskilda organisationer, enheter eller socialarbetare inom välfärdssektorn kan överblicka och hantera hela det mångskiftande fält som socialt arbete utgör. Sammantaget utmynnar detta i antagandet att viss specialisering är mer eller mindre ofrånkomlig (Green et al. 2005, Healy \& Meagher 2007, Stevenson 2005). 
Vilket empiriskt stöd finns då för specialisering? Till att börja med talar ett antal studier för att såväl problem- som funktionsspecialisering kan leda till bättre utredningar. Skogens $(2001,2007)$ har funnit att utredningar av enheter som enbart arbetar med ekonomiskt bistånd förmår att striktare bygga sina bedömningar på enbart ekonomiska förhållanden, medan integrerade organisationer tenderar att väga in även andra bedömningsgrunder. Inom området ekonomiskt bistånd har också särskilt inrättade mottagningsgrupper (dvs. en form av funktionsspecialisering) visat sig vara bättre på att hjälpa de sökande med alternativa lösningar på sina försörjningsproblem (Minas 2005). Fördelar med specialisering i utredningsfasen har också belysts i studier av äldreomsorg (Astvik \& Aronsson 1997, Fuller \& TulleWinton 1996), liksom när det gäller vuxna i psykosocial utsatthet (Cambridge \& Parkes 2006, Cambridge et al. 2011).

Ett argument för funktionsspecialisering inom barnavårdsområdet återfinns i en studie av Bell (1999). Studien visade på svårigheter med att integrera en utredaroch behandlarroll i ett och samma ärende, vilket alltså indirekt förordar funktionsspecialisering. Liknande slutsatser drar Marttila et al. (2012) när det gäller att ha både en utredande och behandlande funktion i arbetet med ekonomiskt bistånd. Vidare har utredningar av specialiserade utredningsenheter inom barnvårdsområdet, visat sig bli slutförda snabbare, ha tydligare frågeställningar och vara mer lättlästa, jämfört med när utredande och behandlande uppgifter är integrerade (Sundell \& Humlesjö 1996). Barnperspektivet tenderar också att vara mer framträdande i utredningar från specialiserade utredningsenheter (Östberg et al. 2000, Östberg, 2010). Att skilja på utredning och behandling har även visat sig kunna inverka positivt på relationerna mellan klienter och de socialarbetare som enbart har den behandlande och stödjande funktionen (Blom 2004, Perlinski 2010).

Det finns ett visst empiriskt stöd för att specialisering är att föredra vid välavgränsade sociala problem (Sandlie et al. 2011). Forskningsresultat talar också för att en allt för bred och integrerad socialtjänst och inte kan hantera alla målgruppers specifika särdrag och behov. Detta blir belyst i studier inom olika områden: bland annat socialtjänstens arbete med spädbarn födda i missbruksmiljö som har svåra medicinska diagnoser (Cohon et al. 2001), cancersjuka i palliativ vård (Levy \& Payne 2006) och flyktingar i utsatta livssituationer (Engstrom \& Okamura 2007). Listan över studier som indikerar ett behov av sådan målgruppsspecialisering kan emellertid göras längre än så. (Se t.ex. Biehal 2005, Green et al. 2005, Hughes et al. 2013, Manning et al. 2004, Parton et al. 1997, Sheppard 2002).

\section{Fragmentisering och bristande helhetssyn - specialiseringens nackdelar}

Samtidigt som specialisering ter sig fördelaktigt vid specifika problem hos individer eller avgränsade målgrupper, gör denna organisationslösning det svårare att rikta arbetet mot bredare folklager, som vid samhällsarbete eller socialt arbete på landsbygden (Murty 2005). Den mest frekventa 
kritiken mot specialisering rör emellertid hur den leder till en fragmentiserad och svåröverblickbar välfärdssektor (Axelsson \& Bihari Axelsson 2006, Bunger 2010, Bømler 2012, Clarfield et al. 2001, Cohon et al. 2001, Levy \& Payne 2006, Matos \& Sousa 2004, Villadsen 2008). När det gäller socialt arbete mer specifikt kan denna fragmentisering göra det svårare att både upptäcka och bistå klienter med komplexa behov (Blom 2004, Christensen \& Egelund 2002, Hassett \& Austin 1997, Sandlie et al. 2011, Spratt 2011, Ungar et al. 2012). En studie av Kuosmanen \& Starke (2013) kan tjäna som illustration. De visar på svårigheterna att uppmärksamma prostitution bland unga personer med intellektuella funktionshinder, då ingen av de myndigheter som möter dessa ungdomar (bl.a. polis, specialskola och socialtjänst) har en fullständig bild av deras leverne och särskilda behov.

Ett annat hinder framträder i studier som visar att specialiserade organisationer, eller enheter i en och samma organisation, kan skilja sig åt när det gäller värderingar, förhållandet till yrkesroll och arbetsuppgifter samt synen på klienter (Drabble 2007, Liljegren 2008, Villadsen 2008, Winter 2009). Bland annat har Meeuwisse et al. (2011) funnit att personal som arbetar med ekonomiskt bistånd i en problemspecialiserad socialtjänst har en större benägenhet till kontroll av klienter, samt krav på motprestationer för bistånd jämfört med de som arbetar inom missbruks- eller barnavårdsområdet. Forskning visar också att arbetet i specialiserade organisationer eller enheter kan få ett instrumentaliserande drag (Bømler 2012), samt att dess perso- nal distanserar sig från sina klienter i högre grad (Söderfeldt 1997, Meeuwisse et al. 2011). Vidare har Minas (2005) funnit att en höggradigt specialiserad organisation innebär fler administrativa barriärer som klienter måste passera för att få tillgång till stöd och hjälp. Dessutom visar studier att professionella inom ett specialiserat barnvårdsfält behöver ägna allt mer tid åt att administrera och realisera samverkan med andra aktörer inom området, på bekostnad av direktkontakten med klienterna (Christensen \& Egelund 2002).

Bärkraftiga relationer mellan socialarbetare och klient ses som en avgörande faktor för framgångsrika stöd- och behandlingsinsatser (Huxley et al. 2009, Knei-Paz 2009). Ovan nämnda avigsidor med organisatorisk specialisering, samt faktumet att den ofta medför att fler professionella involveras i ett och samma ärende, har visat sig utgöra hinder för utvecklingen av sådana relationer (Blom et al. 2009, Villadsen 2008, Winter 2009).

\section{Helhetssyn-ett svårfångat men grundläggande argument för integrering}

Om rationalitet och effektivitet utgör de teoretiska huvudincitamenten för specialisering, så är idén om helhetssyn fundamental för integrering (Perlinski 2010). Denna helhetssyn har dock flera innebörder som kan vara svåra att fånga i en enkel definition (se Bergmark 1998 för en kritisk genomgång av begreppet). En av betydelserna fokuserar emellertid på att människor är mångfacetterade och 
att deras behov inte låter sig delas upp $\mathrm{i}$ några enkla kategorier. Därför innebär helhetssyn även att de organisationer som möter människor med sociala problem inte enbart bör inrikta sig på delsymtom, utan se till hela livssituationen. En annan aspekt av helhetssyn är att människan finns i ett sammanhang (familj, samhälle osv.). Insatser i socialt arbete bör därmed riktas mot såväl individnivå som gruppoch samhällsnivå (Börjeson 2008). Denna syn på sociala problem och socialt arbete var särskilt framträdande i Norden och i större delen av västvärlden under 1960-, 70 -, och i viss mån 80 -talet, vilket även präglade socialtjänstens organisering. Därefter påbörjades utvecklingen mot den specialisering som präglar hela välfärdsområdet idag (Bergmark \& Lundström 2007, Bømler 2012, Dickens 2011). Det finns emellertid tecken på att pendeln långsamt och åtminstone i vissa delar, åter svänger mot integrering. I Storbritannien har staten kommit till slutsatsen att specialiseringen, liksom individualiseringen av sociala problem, har gått för långt. Särskilt har detta drabbat familjer med komplexa behov (Dickens 2011, Parton 2009). Istället för att i linje med problemspecialisering inrikta sig på barn, ekonomi, missbruk eller exempelvis psykisk ohälsa var för sig, behöver insatserna ha ett större inslag av helhetssyn. Denna programmatiska kursändring inom socialpolitiken går under namnet "Think family" (Social Exclusion Task Force 2008). En liknande ambition att skapa en mer sammanhållen välfärd, främst till förmån för klienter med sammansatt problematik - föranledde även den så kallade NAV-reformen i Norge, som inneburit att flera välfärdstjänster sammanförts organisatoriskt och samlokaliserats (Sandlie et al. 2011).

Resten av detta avsnitt fokuserar på det empiriska stödet för integrering i dess mer utpräglade form, närmare bestämt att rikta sig mot ett större fält av sociala problem och utföra flera olika arbetsuppgifter (till exempel både utredningar och stöd/ behandling) i en enstaka organisation eller organisatoriska enhet. Vissa studier indikerar att en integrerad organisation har fördelar i jämförelse med en specialiserad när det gäller stöd- och behandlingsinsatser (Cambridge \& Parkes 2006, Cambridge et al. 2011, Fuller \& Tulle-Winton 1996, Marsh et al. 2005, Astvik \& Aronsson 1999). Det har visat sig fördelaktigt med organisationer som har kompetens och mandat att uppmärksamma klienters totala livssituation vid förändringsarbete, trots att kontakten initierats utifrån snävare problemområden som exempelvis försörjningsproblem (Marttila et al. 2012), ungdomar med komplexa behov (Ungar et al. 2012), eller ungdomskriminalitet (Ryan et al. 2001). När det gäller förutsättningarna för att utveckla bärande relationer mellan socialarbetare och klient visar vissa studier att den integrerade organisationen är mer fördelaktig (Perlinski 2010). Blom et al. (2009) har jämfört uppfattningar hos klienter i specialiserade respektive integrerade organisationer. Man fann bland annat att den integrerade organisationen var lättare att förstå sig på, medförde kontakter med färre socialarbetare, ledde till bättre helhetssyn hos de professionella, samt gjorde klienterna mer involverade och nöjda med hjälpprocessen. 


\section{Bredd på bekostnad av djup- Integreringens avigsidor}

Utvecklingen mot allt mer specialisering inom välfärdssektorn kan rent allmänt tolkas som en reaktion mot eventuella nackdelar med integrering. Empiriskt så har sådana avigsidor bland annat visat sig när det gäller barnavårdsutredningar. Utredningar som utförs i ett integrerat organisationssammanhang tenderar att ta länge tid och vara vagare till sin karaktär jämfört med de som utförs av specialiserade barnavårdsenheter (Sundell \& Humlesjö 1996). I integrerade organisationer riskerar också barnperspektivet att trängas undan av ett mer generellt vuxen- eller familjeperspektiv (Östberg et al. 2000). Avsaknad av tydlig målgrupp i arbetet och specifika kunskaper om barn kan också innebära att professionella istället vänder blicken mot de vuxna, både i barnavårdutredningar och vid planerandet av insatser (Parton et al. 1997). Integrerat utrednings- och behandlingsarbete riskerar också att dölja den makt som finns inbäddad i myndighetsutövning (Christensen \& Egelund 2002).

Erfarenheter från den norska NAVreformen visar att arbetet inom den organisatoriskt integrerade socialtjänsten kan vara tidskrävande och ibland ineffektivt, till exempel när det gäller måluppfyllelse i enskilda ärenden (Helgøy et al. 2011). Vidare innehåller också delar av den forskning som redovisats ovan om målgrupper med problem som är "unika" till sin karaktär (t.ex. Cohon et al. 2001, Biehal 2005, Engstrom \& Okamura 2007, Manning et al. 2004), en indirekt invändning mot att integrering och generalistkunskaper förmår hantera alla de väsensskilda problem som ryms inom det sociala arbetet.

\section{Koordination och kollaboration - styrkor och svagheter}

Medan en fragmentiserad socialtjänst ser ut att vara en av specialiseringens mest framträdande nackdelar, utgör samverkan i vid och allmän betydelse en central motkraft. Begreppet som sådant har tillika en starkt positiv laddning. Detta trots att samverkan mellan aktörer inom välfärdssektorn bland annat visat sig vara tidskrävande och riskerar att äga rum på bekostnad av direkta klientkontakter (Christensen \& Egelund 2002), samt är förbundet med flera andra svårigheter (Se t.ex. Boklund 1995, Danermark \& Kullberg 1999, Hasenfeld 2010b, Hill \& Lynn 2003, Horwath \& Morrison 2007, Ungar et al. 2012). När det gäller såväl inter- som intraorganisatorisk samverkan (Axelsson \& Bihari Axelsson 2006) mellan specialiserade aktörer, så har hinder som enkla missförstånd, oklar ansvarsfördelning, konkurrerande kunskapsanspråk eller kraftmätningar runt tolkningsföreträdet i olika samverkanssituationer uppmärksammats (Blom 2004, Cambridge \& Parkes 2006, Glisson \& Hemmelgarn, 1998, Hitzler \& Messmer 2010, Sandlie et al. 2011, Sousa \& Rodrigues 2009). Framgångsrik samverkan återfinns ofta i olika projekt som kraftsamlar runt en specifik fråga. Effekter över tid har däremot visat sig vara mer blygsamma (Gardner 2003, Glisson \& Hemmelgarn 1998, Hjortsjö 2005, Wihlman 2009).

I denna studie görs emellertid en dis- 
tinktion mellan samverkansformerna koordinering och kollaboration, som kan positioneras utefter kontinuumet mellan specialisering och integrering. Den främsta skillnaden dem emellan är hur element av specialisering respektive intergering balanseras och kommer till utryck (Boklund 1995). Båda dessa organisatoriska lösningar är behäftade med de avigsidor som beskrivits ovan när det gäller samverkan rent generellt. Men de har också, var för sig, sina dokumenterade fördelar.

Till att börja med finns empiriskt stöd för att koordinera, eller samordna insatser inom socialtjänstområdet, bland annat när det gäller klienter med komplexa behov. Koordinerade insatser från flera specialiserade aktörer ger ett bättre utfall jämfört med specialisering utan formaliserade ansatser till koordinering. (Buck et al. 2011, Marsh et al. 2005, Nix et al. 2005, Ungar et al. 2012). Att inrätta särskilda tjänster (som case managers, welfare advisors, behandlingssamordnare, service co-ordinators eller liknade) med ansvar för koordination av insatser, har också visat sig förbättra utfallet för klienter med parallella insatser från flera specialiserade aktörer (Cambridge \& Parkes 2006, Cambridge et al. 2011, Huxley et al. 2009, Levy \& Payne 2006).

När det gäller nästa steg mot renodlad integrering, kollaboration, har studier inom socialtjänstens område visat hur aktörer med skilda organisatoriska hemvister och i grunden olika kompetenser, kan göra skillnad genom att arbeta tillsammans. I detta fall sker en viss uppluckring av gränsdragningen mellan respektive aktörers ursprungliga organisatoriska-, samt kunskaps-, och metodmässiga specialisering.
Det integrerande draget består i att aktörerna tillsammans bildar ett flerdimensionellt stöd- och behandlingsalternativ, som riktar sig mot en avgränsad och gemensam målgrupp. Här är vanligen ambitionen att synergieffekter ska uppstå, det vill säga att värdet av det gemensamma arbetet ska bli större än att enbart addera ett antal insatser, som vid koordination. Denna mellanväg $i$ valet mellan specialisering och integrering har visat sig vara gynnsam i arbetet med särskilt utsatta målgrupper. Till exempel när det gäller hemlöshet (Rosenheck et al. 2001) eller familjer där barnvårdsinsatser behöver kombineras med insatser mot fattigdom, missbruk samt psykisk och fysisk ohälsa (Cohon et al. 2001, Marsh et al. 2005, Osterling \& Austin 2008, Robertson \& Haight 2012, Social exclusion task force 2008, Spratt 2011).

\section{Sammanfattning av studiens resultat}

Syftet med artikeln är att sammanfatta och diskutera kunskapsläget när det gäller hur olika organisationsstrukturer inverkar på det arbete som utförs inom svensk socialtjänst och dess internationella motsvarigheter. Det redovisade materialet kommer från en tämligen bred litteratursökning, då studier som explicit undersöker specialisering eller integrering är relativt få. Sökningen har därför vidgats till studier där dessa frågor behandlas mer eller mindre implicit, vilket i sin tur medfört en relativt stor olikhet mellan de empiriska studier som ingår i materialet. Forskningsgenomgången kan inte betraktas som fullständig 
eller heltäckande och de iakttagelser som görs här ska ses som tentativa. Med detta förbehåll kan ändå några av de mer centrala resultaten sammanfattats på följande sätt i figur 2. I figuren beskrivs fördelar (+) med specialisering, koordination, kollaboration samt integrering ovanför den pil som illusterar kontinuumet av organisatoriska lösningar. Motsvarande nackdelar (-) beskrivs under pilen.

\section{Hurbör socialtjänsten organiseras?}

Denna fråga ges som synes inga entydiga svar här. Resultatet antyder ändå att den idag utbredda specialiseringens främsta fördel, är möjligheten att utveckla expertis inom ett avgränsat område, med högre kvalitet och bättre resultat som förväntad konsekvens. Ökad specialisering och diversifiering av expertis, ökar också möjligheten att bemöta fler "unika" och avgränsade målgrupper med specifika behov. En allt mer specialiserad välfärd ser tillika ut att ha stöd i relativt breda lager, och har drivits fram - eller åtminstone inte motarbetats av majoriteter på såväl den politiska nivån, som inom socialarbetaprofessionen (Perlinski 2010). Det finns emellertid även skäl att ifrågasätta ändamålsenligheten med

\section{Fig. 2.}

Tentativ sammanfattning av för-och nackdelar med olika organisatoriska lösningar utefter ett kontinuum mellan specialisering och integrering.

Specifika målgruppsoch metodkunskaper (expertis)

Fördelaktigt vid unika, välavgränsade problem

Utredningar med bra kvalitet

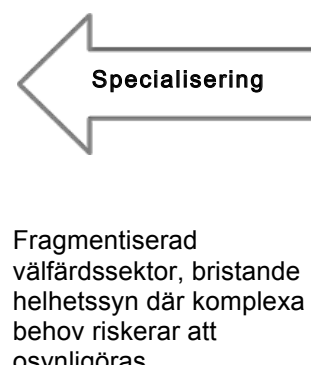

- osynligöras

Fler socialarbetare involveras

Hinder för bärande relationer
Uppluckrade gränser
mellan aktörer -
eventuella
synergieffekter

Möjligt att gemensamt möta komplexa behov inom särskilt utsatta målgrupper
Möjliggör

helhetssyn, samt att komplexa behov kan synliggöras

Färre socialarbetare involveras

målgrupps- och metodkunskaper bibehålls
Gynnsam grund för bärande relationer 
långtgående specialisering inom socialtjänstområdet. Kritiken mot en fragmentiserad välfärd är tämligen omfattande. Förmodligen skulle frågan om socialtjänstens organisering, tjäna på att studeras och diskuteras utifrån andra utgångspunkter än just spänningsfältet mellan specialisering och integrering. Bland annat på grund av att den integrerade organisationsstrukturen i realiteten för en tynande tillvaro, samtidigt som den också har sina dokumenterade avigsidor.

Vidare kan det vara rimligt att betrakta renodlad specialisering och integrering som idealtyper. Det är svårt att hitta specialiserade, helt solitära organisationer eller enheter. Detsamma gäller dess integrerade motsvarigheter med någon form av allomfattande ansvar för sociala problem. Svaret på frågan om den mest gynnsamma organisationsstrukturen verkar istället dväljas någonstans i engelskans vittgående begrepp service integration, liksom i vår svenska motsvarighet samverkan. Resultatet av litteraturgenomgången indikerar att det inte finns någon enskild och optimal organisationsstruktur för socialtjänsten. Istället ser rätt "mix" eller balans mellan specialisering och integrering i olika behovssituationer ut att vara eftersträvansvärt, om än svåruppnåeligt. Med ett begrepp lånat från Ungar et al. (2012) kan detta utryckas som att flera olika service- eller behandlingskonfigurationer måste vara möjliga för att kunna nå framgång.

Orsaken till att frågan om samverkan överhuvudtaget är aktuell inom socialtjänstområdet, är enkelt uttryckt att individers livssituation, samt därigenom omfattningen och komplexiteten på deras sociala pro- blem, inte alltid kan avgränsas och sorteras utifrån de organisatoriska gränsdragningarna. Ett positivt sätt att se på samverkan i detta avseende är att fördelarna med avgränsade kompetenser och arbetsuppgifter behålls, samtidigt som nackdelarna till viss del kan neutraliseras. Mer specialisering betyder med detta synsätt, även "mer" stöd och vård eller behandling per individ (Buck et al. 2011). Så verkar också statsmakterna i länder som USA, Storbritannien, Australien och Sverige se på saken idag. Specialisering framstår där som en mer eller mindre självklar grundpremiss för det sociala arbetet. När vissa problem ändå synliggörs, föreskrivs regelmässigt samverkan som motåtgärd (Buck et al. 2011, Horwath \& Morrison 2007, Socialdepartementet 2012, Social Exclusion Task Force 2008). Att uppnå de vanligtvis högt ställda förväntningarna på samverkan, har i forskningen dock visat sig vara lättare sagt än gjort. Man kan i anslutning till detta undra i vilken mån en organisationsstruktur behöver matcha behovsprofilen hos socialtjänstens klienter. En specialiserad organisation ser hursomhelst ut att passa som allra bäst då behoven är avgränsade och enstaka. Frågan är emellertid hur stora förhoppningar det är rimligt att ha på samverkan i de mer komplexa fallen, samt vilken organisationsstruktur som egentligen bäst återspeglar behoven hos socialtjänstens klienter?

\section{Fortsatt forskning - utmaningar och uppslag}

När det gäller svenska förhållanden är det av flera anledningar svårt att studera hur 
socialtjänstens organisationsstruktur inverkar på klientarbetet. Initialt finns svårigheten att designa studier som förmår fånga sådana samband. Kanske är detta också en av anledningarna till att området fortfarande inte är särskilt beforskat, trots att forskarsamhället har pekat ut det som både viktigt och eftersatt. En annan svårighet är relaterad till att nästan varje kommun har sin egen unika organisationslösning. Men enligt en studie av Lundgren et al. (2009), är så många som 256 av Sveriges 290 kommuners individ- och familjeomsorg organiserade utifrån problemspecialisering. Kanhända finns det trots allt sådana generella drag hos de olika kommunala socialtjänstorganisationerna, att det är möjligt att tala om svensk socialtjänst som ett någorlunda enhetligt fenomen. För att kunna ha någon åsikt om passformen mellan klienters behov och socialtjänstens organisation behövs emellertid betydligt bättre kunskap om karaktären, omfattningen och komplexiteten när det gäller behoven hos socialtjänstens klienter. Officiell statistik (se t.ex. Socialstyrelsen 2012a, 2012b) redovisar målgrupper och olika typer av insatser separat. Ingenstans går att utläsa $i$ vilken mån individer har flera parallella behov, eller i vilken mån komplexa behov förekommer i en och samma familjebildning. Medan man i England bland annat stöder sin uppmaning "Think family" på data som visar att två procent av landets socialt utsatta familjer har synnerligen svåra och komplexa problem (Social Exclusion Task Force 2008), saknas motsvarande kunskap i Sverige.

Socialtjänstens klienter kommer rent generellt, sällan till tals i forskningen. Detta faktum avspeglar sig även i det material som samlats in för denna artikel. Endast ett fåtal av de refererade studierna har ett klientperspektiv, i meningen att de själva fått uttrycka sin uppfattning i frågor kopplade till socialtjänstorganisationers utformning och verkningar. Att försöka fylla denna kunskapslucka borde avslutningsvis vara en av de mer angelägna uppgifterna för framtida forskning, om ambitionen är att öka kunskapen om vilken betydelse organisationsstrukturen har för socialtjänstens klientarbete.

\section{Referenser}

Andersson, G., \& Sallnäs, M. (2007). Svensk barnavårdsforskning: en översikt över ett och ett kvarts års forskningsproduktion. Socionomen, forskningssupplement: 6, 10-34.

Astvik, W., \& Aronsson, G. (1999). Home care workers as specialists or generalists - quality in work and care, Proceedings/Work, Stress and Health 99, Organization of Work in a Global Economy, 11-13 March 1999, Baltimore, Maryland, USA.

Axelsson, R., \& Bihari Axelsson, S. (2006). Inte- gration and collaboration in public health-a conceptual framework. International Journal of Health Planning \& Management, 21(1), 75- 88. Bell, M. (1999). Working in partnership in child protection: The conflicts. The British Journal of Social Work, 29(3), 437-455.

Bergmark, Å. (1998). Nyckelbegrepp $i$ socialt arbete. Lund: Studentlitteratur.

Bergmark, A., \& Lundstrom, T. (2007). Unitarian ideals and professional diversity in social work practice - the case of Sweden. European Jour-

Grell, Ahmadi \& Blom: Hur inverkar organisationsstrukturen på... 
nal of Social Work, 10(1), 55-72.

Bergmark, Å., \& Lundström, T. (2005). En sak i taget?: Om specialisering inom socialtjänstens individ- och familjeomsorg. Socialvetenskaplig tidskrift.12:2-3, 125-148.

Biehal, N. (2005). Working with adolescents at risk of out of home care: The effectiveness of specialist teams. Children and Youth Services Review, 27(9), 1045-1059.

Blom, B. (2004). Specialization in social work practice - effects on interventions in the personal social services. Journal of Social Work. 4:1, 25-46.

Blom, B., Perlinski, M., \& Morén, S. (2009). Organisational structure as barrier or support in the personal social services? Results from a client survey. Dilemmas for Human Services 2009: Papers Presented at: The 13th International Research Conference "Breaking Down the Barriers", Staffordshire University, 10 - 11 September 2009 (Revised Version October 2009).

Boehm, A., \& Yoels, N. (2009). Effectiveness of welfare organizations: The contribution of leadership styles, staff cohesion, and worker empowerment. The British Journal of Social Work, 39(7), 1360-1380.

Boklund, A. (1995). Olikheter som berikar?: Möjligheter och hinder $i$ samarbetet mellan socialtjänstens äldre- och handikappomsorg, barnomsorg samt individ- och familjeomsorg. Diss. Stockholm: Stockholms Universitet.

Bømler, T. (2012). Fra specialisering - og tilbage til specialisering: Organiseringen af socialt arbejde i kommunerne efter kommunalreformen. Tidsskrift for forskning og praksis $i$ socialt arbejde, 24, 5-13.

Börjeson, B. (2008). Förstå socialt arbete (1. uppl. ed.). Malmö: Liber.

Bryman, A. (2011). Samhällsvetenskapliga metoder. 2., [rev.] uppl. Malmö: Liber.

Buck, A., Seale, E., Leiter, J., \& Taylor, T. (2011). Differentiation and integration of welfare-towork service delivery in North Carolina. Administration in Social Work, 35(5), 475-493.

Bunger, A. C. (2010). Defining service coordination: A social work perspective. Journal of
Social Service Research, 36(5), 385-401.

Cambridge, P., \& Parkes, T. (2006). The tension between mainstream competence and specialization in adult protection: An evaluation of the role of the adult protection co-ordinator. British Journal of Social Work, 36(2), 299-321.

Cambridge, P., Beadle-Brown, J., Milne, A., Mansell, J., \& Whelton, B. (2011). Adult protection: The processes and outcomes of adult protection referrals in two English local authorities. Journal of Social Work, 11(3), 247-267.

Christensen, E., \& Egelund, T. (2002). Børnesager : Evaluering af den forebyggende indsats. København: Socialforskningsinstituttet.

Clarfield, A. M., Bergman, H., \& Kane, R. (2001). Fragmentation of care for frail older people - an international problem. Experience from three countries: Israel, Canada, and the United states. Journal of the American Geriatrics Society, 49(12), 1714-1721.

Cohon, J. D., Fritz, D., Brady, M., Cooper, B. A., Needell, B., \& Smith, K. K. (2001). Specialized foster care for medically complex, drugexposed, HIV positive infants: The baby moms program. Children and Youth Services Review, 23(11), 831-863.

Collins, J.A., \& Fauser, B.C.J.M. (2005). Editorial: balancing the strengths of systematic and narrative reviews. Human Reproduction Update, $11(2), 103-110$.

Danermark, B., \& Kullberg, C. (1999). Samverkan: Välfärdsstatens nya arbetsform. Lund: Studentlitteratur.

Dickens, J. (2011). Social work in England at a watershed-as always: From the Seebohm report to the social work task force. British Journal of Social Work, 41(1), 22-39.

Dellgran, P., \& Höjer, S. (2011). Nya trender och gamla mönster. Doktorsavhandlingarna i socialt arbete 1980-2009. Socialvetenskaplig tidskrift. 18:2, 85-106.

Drabble, L. (2007). Pathways to collaboration: Exploring values and collaborative practice between child welfare and substance abuse treatment fields. Child Maltreatment, 12(1), 31-42. 
Engstrom, D. W., \& Okamura, A. (2007). A nation of immigrants: A call for a specialization in immigrant well-being. Journal of Ethnic \& Cultural Diversity in Social Work, 16(3-4), 103111.

Eriksson, G. (1989). Platon \& smitaren : Vägar till idéhistorien. Stockholm: Atlantis.

Eriksson-Zetterquist, U., Kalling, T., \& Styhre, A. (2006). Organisation och organisering (2., [utök.] uppl. ed.). Malmö: Liber.

Fayol, H. (1916). General Principles of Management. I Organization theory: Selected classic readings (2007). In Pugh D. S. (Ed.), (5. ed.). London: Penguin.

Fisher, M. P., \& Elnitsky, C. (2012). Health and social services integration: A review of concepts and models. Social Work in Public Health, 27(5), 441-468.

Fuller, R., \& Tulle-Winton, E. (1996). Specialism, genericism and others: Does it make a difference? A study of social work services to elderly people. British Journal of Social Work, 26(5), 679-698.

Gardner, R. (2003). Working together to improve children's life chances: The challenge of interagency collaboration. I Weinstein, J., Whittington, C., \& Leiba, T. (red) (2003). Collaboration in social work practice, London: Jessica Kingsley Publishers Ltd.

Glisson, C., \& Hemmelgarn, A. (1998). The effects of organizational climate and interorganizational coordination on the quality and outcomes of children's service systems. Child Abuse \& Neglect, 22(5), 401-421.

Green, G., Thorpe, J., \& Traupmann, M. (2005). The sprawling thicket: Knowledge and specialisation in forensic social work. Australian Social Work, 58(2), 142-153.

Hasenfeld, Y. (2010a). Introduction. I Hasenfeld, Y. (Red). (2010). Human services as complex organizations (2. ed.). Los Angeles: Sage.

Hasenfeld, Y. (2010b).Worker-client relations: social policy in practice. I Hasenfeld, Y. (Red). (2010). Human services as complex organizations (2. ed.). Los Angeles: Sage.

Hassett, S., \& Austin, M. J. (1997). Service integra- tion: Something old and something new. Administration in Social Work, 21(3), 9-29.

Healy, K., \& Meagher, G. (2007). Social workers' preparation for child protection: Revisiting the question of specialisation. Australian Social Work, 60(3), 321-335.

Helgøy, I., Kildal A., \& Nilssen E. (2011). Mot en spesialisert veilederrolle i NAV? En dokumentasjonsrapport. Uni Rokkansenteret, UNI research. Notat 12-2011

Hill, C. J., \& Lynn Jr., L. E. (2003). Producing human services. Public Management Review, 5(1), 63-81.

Hitzler, S., \& Messmer, H. (2010). Group decisionmaking in child welfare and the pursuit of participation. Qualitative Social Work, 9(2), 205226.

Hjortsjö, M. (2005). Med samarbete i sikte : Om samordnade insatser och samlokaliserade famil jecentraler. Diss. Lund: Lunds universitet.

Horwath, J., \& Morrison, T. (2007). Collaboration, integration and change in children's services: Critical issues and key ingredients. Child Abuse \& Neglect, 31, 55-69.

Hsieh, H., \& Shannon, S. E. (2005). Three approaches to qualitative content analysis. Qualitative Health Research, 15(9), 1277-1288.

Hughes, A., Hope, R. L., Nwokolo, N., Ward, B., Jones, R., Von Schweitzer, M., et al. (2013). Meeting complex needs: Young people with HIV in london. HIV Medicin, 14(3), 145-152.

Huxley, P., Evans, S., Beresford, P., Davidson, B., $\&$ King, S. (2009). The principles and provision of relationships: Findings from an evaluation of support, time and recovery workers in mental health services in England. Journal of Social Work, 9(1), 99-117.

Johansson, S. (2005). Socialtjänstens organisation som forskningsobjekt. Socialvetenskaplig tidskrift no 2-3. 1104-1420.

Knei-Paz, C. (2009). The Central Role of the Therapeutic Bond in a Social Agency Setting: Clients' and Social Workers' Perceptions. Journal of Social Work, 9: 178-198.

Kuosmanen, J., \& Starke, M. (2013). Identifying the invisible: The experiences of prostitution

Grell, Ahmadi \& Blom: Hur inverkar organisationsstrukturen på... 
among persons with intellectual disabilities: Implications for social work. Journal of Social Work, 13(2), 123-140.

Lawrence, P. R., \& Lorsch, J. W. (1967). Organization and environment : Managing differentiation and integration. Boston, Mass.

Levy, J., \& Payne, M. (2006). Welfare rights advocacy in a specialist health and social care setting: A service audit. British Journal of Social Work, 36(2), 323-331.

Liljegren, A. (2008). Professionellt gränsarbete: Socionomexemplet. Diss. Göteborg: Göteborgs universitet.

Lundgren, M., Blom, B., Morén, S., \& Perlinski, M. (2009). Från integrering till specialisering : Om organisering av socialtjänstens individ- och familjeomsorg 1988-2008. Socialvetenskaplig tidsskrift 2, 162-183.

Manning, M. C., Cornelius, L. J., \& Okundaye, J. N. (2004). Empowering african americans through social work practice: Integrating an afrocentric perspective, ego psychology, and spirituality. Families in the Society - the Journal of Contemporary Human Services, 85(2), 229235.

Marsh, J. C., Ryan, J. P., Choi, S., \& Testa, M. F. (2005). Integrated services for families with multiple problems: Obstacles to family reunification. Children and Youth Services Review, 28, 1074-1087.

Martin, L., \& Hazlett-Knudsen, R. (2012). Change and continuity in state human service agencies: 1986-2006. Administration in Social Work, 36(1), 85-100.

Marttila, A., Johansson, E., Whitehead, M., \& Burström, B. (2012). Dilemmas in providing resilience-enhancing social services to long-term social assistance clients. A qualitative study of swedish social workers. BMC Public Health, 12(1), 517-527.

Matos, A. R., \& Sousa, L. M. (2004). How multiproblem families try to find support in social services. Journal of Social Work Practice, 18(1), 65-80.

Meeuwisse, A., Scaramuzzino, R., \& Sward, H. (2011). Everyday realities and visionary ideals among social workers in the nordic countries: A matter of specialization and work tasks? Nordic Social Work Research, 1:1, 5-23.

Minas, R. (2005). Administrating poverty: Studies of intake organization and social assistance in sweden. Diss. Stockholm: Stockholms universitet.

Murty, S. A. (2005). The future of rural social work. Advances in Social Work, 6(1), 132-144.

Nix, R. L., Pinderhughes, E. E., Bierman, K. L., \& Maples, J. L. (2005). Decoupling the relation between risk factors for conduct problems and the receipt of intervention services: Participation across multiple components of a prevention program. American Journal of Community Psychology, 36(3-4), 307-325.

Osterling, K. L., \& Austin, M. J. (2008). Substance abuse interventions for parents involved in the child welfare system: Evidence and implications. Journal of Evidence-Based Social Work, 5(1-2), 157-189.

Parton, N. (2009). From Seebohm to think family: Reflections on 40 years of policy change of statutory children's social work in england. Child and Family Social Work, 14(1), 68-78.

Parton, N., Thorpe, D., \& Wattam, C. (1997). Child protection: Risk and the moral order. Basingstoke: Macmillan.

Perlinski, M. (2010). Skilda världar: Specialisering eller integration $i$ socialtjänstens individ- och familjeomsorg. Diss: Umeå: Umeå universitet.

Robertson, A. S., \& Haight, W. (2012). Engaging child welfare-involved families impacted by substance misuse: Scottish policies and practices. Children and Youth Services Review, 10, 1992-2001.

Rosenheck, R., Morrissey, J., Lam, J., Calloway, M., Stolar, M., Johnsen, M., et al. (2001). Service delivery and community: Social capital, service systems integration, and outcomes among homeless persons with severe mental illness. Health Services Research, 36(4), 691-710.

Ryan, J. P., Davis, R. K., \& Yang, H. (2001). Reintegration services and the likelihood of adult imprisonment: A longitudinal study of adjudicated delinquents. Research on Social Work 
Practice, 11(3), 321-337.

Sandlie, H.C., Langsether, Å. Sørvoll, J. Skårberg, A., \& Hansen, T. (2011). Organisering og planlegging av boligsosialt arbeid i norske kommuner - fire casestudier. Norsk institutt for forskning om oppvekst, velferd og aldring. NOVA Rapport 5/2011

Scott, W. R. (2003). Organizations: Rational, natural, and open systems (5. ed. ed.). Upper Saddle River, N.J.: Prentice Hall.

Sheppard, M. (2002). Depressed mothers' experience of partnership in child and family care. British Journal of Social Work. 32(1), 93-112.

Shier, M., L., \& Graham, J., R. (2011). Work-related factors that impact social work practitioners' subjective well-being: Well-being in the workplace. Journal of Social Work, 11(4), 402-421.

Shim, M. (2009). Factors influencing child welfare employee's turnover: Focusing on organizational culture and climate. Children and Youth Services Review, 32, 847-856.

Skogens, L. (2001). Olika organisationsformer - olika bemötanden: En vinjettstudie av socialsekreterares bemötande och bedömning av socialbidragstagare med begynnande alkoholproblem. Stockholm: Univ., Institutionen for socialt arbete.

Skogens, L. (2007). Hur bemöts manliga socialbidragstagare med alkoholproblem? : regler, kunskap och kontext i socialt arbete. Diss. Stockholm: Stockholms universitet.

Socialdepartementet. (2012). Stärkt stöd och skydd för barn och unga. Lagrådsremiss. 14 juni 2012.

Social Exclusion Task Force. (2008). Think Family: Improving the life chances of families at risk. London: Social Exclusion Task Force, Cabinet Office.

Socialstyrelsen. (2012a). Barn och unga - insatser år 2011 - Vissa insatser enligt socialtjänstlagen (SoL) och lagen med särskilda bestämmelser om vård av unga ( $L V U)$.

Socialstyrelsen. (2012b). Insatser år 2011 för vuxna personer med missbruks- och beroendeproblem och för övriga vuxna.

Sousa, L., \& Rodrigues, S. (2009). Linking formal and informal support in multiproblem low- income families: The role of the family manager Journal of Community Psychology, 37(5), 649662.

Spratt, T. (2011). Families with multiple problems: Some challenges in identifying and providing services to those experiencing adversities across the life course. Journal of Social Work, 11(4), 343-357.

Stevenson, O. (2005). Genericism and specialization: The story since 1970. British Journal of Social Work, 35(5), 569-586.

Sundell, K., \& Humlesjö, E. (1996). Sociala utred ningar med fokus på barn. Stockholm: Socialtjänsten, FoU-byrån.

Söderfeldt, M. (1997). Burnout? Diss. Lund: Lunds universitet.

Ungar, M., Liebenberg, L., \& Ikeda, J. (2012). Young people with complex needs: Designing coordinated interventions to promote resilience across child welfare, juvenile corrections, mental health and education services. British Journal of Social Work. October 7, 1-19.

Weber, M. (1924). Legitimate Authority and Bureaucracy. I Organization theory: Selected classic readings (2007). In Pugh D. S. (Ed.), (5. ed.). London: Penguin

Villadsen, K. (2008). 'Polyphonic' welfare: Luhmann's systems theory applied to modern social work. International Journal of Social Welfare, $17(1), 65-73$

Wihlman, U. (2009). Development of interorganisational integration: A vocational rehabilitation project. Diss. Göteborg: Nordic School of Public Health.

Winter, K. (2009). Relationships matter: The problems and prospects for social workers' relationships with young children in care. Child \& Family Social Work 14(4), 450-460.

Östberg, F. (2010). Bedömningar och beslut- Från anmälan till insats $i$ den sociala barnavården. Diss. Stockholm: Stockholms universitet.

Östberg, F., Wåhlander, E., \& Milton, P. (2000). Barnavårdsutredningar i sex kommuner: En vinjettstudie ([Ny, rev. uppl.] ed.). Stockholm: Centrum för utvärdering av socialt arbete, Socialstyrelsen (CUS).

Grell, Ahmadi \& Blom: Hur inverkar organisationsstrukturen på.. 


\section{Summary}

\section{What impact does the organizational structure have on work with clients in the social services? A research review}

There is a clear trend towards specialization within social work. Although it is common for the social services to be divided into several units and functions, there is a lack of empirical evidence concerning the benefits of this organizational solution. The aim of this article is to summarize and discuss the research field of organizational structures in the social services and their impact on work with clients.

Advantages and disadvantages related to different ways of organizing the social services are identified on a sliding scale of diverse organizational solutions - from high levels of specialization to the contrasting high levels of integration. Empirical evidence that speaks both for and against specialization and integration, as well as coordination and cooperation, is presented. The main conclusion is that an efficient social service organization might need to combine and balance aspects of both specialization and integration. Different kinds of "service configurations" that reflect the specific needs of certain clients or groups of clients may also be important. Finally, the need for more research about how clients experience social services organizations is emphasized. 